\title{
Ordinary Biodiversity, Local Stakeholders and Forest Management as a Driver for Regional Sustainable Development
}

\author{
Hervé Brédif, Laurent Simon \\ Université Paris 1 Panthéon-Sorbonne, UMR LADYSS CNRS, Institut de Géographie, Paris, France \\ Email: hbredif@univ-paris1.fr, Isimon@univ-paris1.fr
}

Received 25 February 2014; revised 27 March 2014; accepted 6 April 2014

Copyright (C) 2014 by authors and Scientific Research Publishing Inc.

This work is licensed under the Creative Commons Attribution International License (CC BY).

http://creativecommons.org/licenses/by/4.0/

c) (i) Open Access

\begin{abstract}
The protection of biodiversity which had long been bounded up with emblematic "natural" spaces is now increasingly focusing on ordinary biodiversity and rural agricultural land and forests as well as on urban and peri-urban spaces. Such ordinary biodiversity has its own specific features which make it both a relative and uncertain topic of research. Traditional nature protection instruments do not work on this dimension of the planet's living tissue and new tools need to be deployed in conjunction with regional and local stakeholders that will provide long-term sustainable solutions for biodiversity and for local and regional development more generally. Research conducted on the Plateau de Millevaches explores the possibilities for shared caring for this biodiversity.
\end{abstract}

\section{Keywords}

Biodiversity Conservation, Forest, Stakeholder Participation, Decision Making

\section{Introduction}

The protection of biodiversity which had long been bounded up with emblematic "natural" spaces is now increasingly focusing on ordinary biodiversity spaces, in particular the forest spaces. The willingness to develop policies to protect all types of forest habitats has been borne out in the national biodiversity strategy of 20032004 (SNB) as well as in the government-sponsored Grenelle environmental conference (2009). But such ordinary biodiversity spaces are also subjected to the practices and uses of local stakeholders who would appear to have an essential role in the deployment and sustainability of any policies put forward (Lynam et al., 2007). And yet there has been little research into the biodiversity-related priorities and wishes of these stakeholders that would enable them to become active policy-making partners and not merely the reluctant implementers of deci- 
sions that have come from above (Arnstein, 1969; Rowe \& Frewer, 2000; Reed, 2008; Stringer et al., 2006). Factoring in ordinary biodiversity requires a radical rethink of long-dominant conservation and/or land banking policies. Territory becomes the key framework in this new approach leading to a re-examination of citizen participation in the management of living matter, forest in particular. The research programmes conducted on the Plateau de Millevaches demonstrate that it is possible to rally local stakeholders around this notion of ordinary biodiversity in order to develop a genuine cared-based approach to local forest biodiversity that will underpin local and regional sustainable development.

\section{Ordinary Biodiversity and Its Specific Features}

Ordinary biodiversity is the "living tissue of the planet" (Barbault, 2006) comprising both a considerable number of species (nearly two million animal and vegetable species are known at present-only a tiny portion of the total) as well as the competition-dependency- and cooperation-type relationships (Bastolla et al., 2009) that structure ecosystems. In other words, this biodiversity cannot be reduced to just figures and indicators; it is first and foremost a complex body of relationships. As such, ordinary nature comprises the bulk of existing biodiversity of which homo sapiens is just one of the species.

It therefore has three characteristics which means that it is perceived in a radically different manner from the approach still in vogue in biodiversity-related policies.

First, it is very widespread in "relatively anthropized" forest as well as in artificialised ones. This biodiversity is not restricted to parks or remarkable areas, it is present everywhere. Consequently, it is often a day-to-day biodiversity, experienced by the entire population and which constitute their day-to-day landscape. So, this biodiversity is not a mere topic of research or contemplation but a participating element in the subjectivity of individuals. Because it is present day to day, widespread and generally accessible, it is used and appropriated by a large number of stakeholders: forest owners, logger, hikers, tourists or mushroom pickers. The more "remarkable" biodiversity is, the more isolated, reserved and regulated it is; but the more ordinary biodiversity is, the more it concerns everyone.

Seen as such, the planet's living tissue provides the support for all biodiversity. After having long considered landscape matrix as repellent or neutral at best (MacArthur \& Wilson, 1967), landscape ecology research now highlights its importance in maintaining biodiversity in general, and remarkable biodiversity in particular. The most recent research has demonstrated that the response of different species to landscape characteristics depends not merely on patches of remarkable habitats but also on the heterogeneity of the landscape (Foltête et al., 2012; Fahrig, 2010) and the very configuration of this matrix (Mimet et al., 2013). The habitat-matrix dichotomy that used to underpin landscape ecology has now been overtaken by a more global approach that makes ordinary biodiversity-that which is present in the matrix-an essential factor in the overall diversity of living matter. These considerations are now all the more important given that climate change in progress stresses the necessity for all animal and plant species to be able to move around in order to adapt. However, the very possibility of this mobility largely depends on the quality of the spaces under consideration, not just biological corridors but the surrounding forest mosaics. Research by Gaston and Fuller (2008) and Lennon (2011) confirmed this importance of "common" species and spaces in preserving overall ecological diversity. The decline in common species is potentially riskier than the disappearance of such and such a rare species. This support function is so important that we now consider that it is through the evaluation of this ordinary biodiversity that we can understand the overall dynamics of biodiversity most effectively. The STOC program (survey of common birds over time) coordinated by the French Natural History Museum (Julliard et al., 2006) reflects this dimension by stressing the progress of general species in France at the expense of specialist forestry and agricultural species. And although indicators based on rare or endangered species provide vital data for detecting tiny changes, these are hard to apply on a general basis and must be cross-checked with these ordinary biodiversity indicators.

Finally, as Godet (2010) points out, ordinary nature "provides humanity with the most resources". The ecosystem services approach to biodiversity which seeks to focus on biodiversity values (i.e., economic as well as heritage value) has stressed the importance of resources issued from biodiversity use. Above all, it is day-to-day, ordinary biodiversity that provides the bulk of regulation services (carbon sequestration, air and water quality, etc.), supply services (timber, game, non-timber products, etc.) and cultural services (recreation and tourism values, aesthetic and sentimental dimensions, etc.). The economic aspect can be considerable if we factor in the activities that are contingent on such ordinary biodiversity: wood industries, hunting, green tourism etc. 
This society-ordinary biodiversity link has become a key vector in public policy making. France's 2012 National biodiversity strategy states that "the overall objective is therefore to preserve remarkable biodiversity... as much as ordinary biodiversity".

However, while getting beyond the confines of remarkable biodiversity does seem necessary, the implications of such a change in paradigm need to be measured. Ordinary biodiversity requires adjustments to the tools and concepts used for protecting and conserving forest that have predominated for decades. Whereas remarkable biodiversity is clearly identified, scientifically grounded and validated by experts, ordinary biodiversity is more difficult to circumscribe in any unequivocal manner. While the former is compartmentalised and identified in designated spaces (parks, reserves, etc.), the second eludes any predefined spatial breakdown. Moreover, while one is managed by a single or dominant stakeholder, the other is handled by a plethora of actors with multiple aspirations and perceptions. So biodiversity has become genuinely diverse-diverse stakeholders, values and projects-and it is this overall diversity and not merely ecological diversity that needs to be taken into consideration.

\section{A New Approach to Biodiversity Characterised by Relativity}

Although, as we have pointed out, the value of services provided by ordinary biodiversity in forest is considerable, their exact value remains highly relative. Aside from the debates that exercise the minds of biodiversity economists, such relativity is down to several factors relating to:

The complexity of ecological processes. Everyone agrees on the positive role of riparian forest in treating water from catchment areas with high levels of chemical inputs, but the service provided here results more from a (soil-river-forest) interface than from any readily identifiable ecosystem. What are the respective roles of trees, microbial communities and abiotic soil components? A series of ecosystems, i.e., an eco-complex (Blandin, 1992) are often at the origin of the service provided (Chevassus-au-Louis, 2012). Even with clearly identified ecosystems, the benefits of biodiversity are still a subject of debate as their modus operandi and productivity are not strictly correlated (Thompson \& Starzomski, 2006). Finally, there are relatively undifferentiated yet highly resilient ecosystems: despite being one of the world's most homogeneous ecosystems, the Canadian boreal forest has proved remarkably resistant to upheavals (fires, insects, etc.).

Persisting uncertainty over the link between biodiversity and ecosystem services. Although ecosystems do indeed lie at the heart of significant services provided to society, the role of biodiversity in such services is not systematic and is nearly always hard to quantify. What is the part of the species diversity in the storage of carbon of a forest? Few studies allow today to bring a clear answer.

Therefore, although it is difficult to accurately quantify the contribution of ordinary biodiversity to ecosystem services provided, it is just as hard to ascribe it a value that makes sense other than in relation to an evaluator. Ordinary biodiversity is more akin to a continuum. While protecting the Giant Sequoia of the Sierra Nevada in California is recognised as resulting from an intrinsic and (virtually) unchallenged existence value, the same cannot be said of ordinary elements (a copse) whose value is always doubly relative: relative both to the other elements of the habitat (of varying degrees of rarity and playing roles of varying ecological importance) and to the stakeholders concerned. Unless labelled as exceptional, the ordinary forest becomes a source of differentiated and even diverging evaluations. "The wood behind my house" may be both a place for picking mushrooms or gathering wood, a land reserve or a carbon sink. Its usefulness is both local and planetary, its value contingent on the stakeholders that appropriate it and incorporate it into their project.

Therefore, once we focus on the importance to be accorded to ordinary diversity in forest, uncertainty and relativity become central dimensions. For the moment, the oft-cited link between well-being and biodiversity has barely been verified. International research publications that actually demonstrate a positive correlation between forest biodiversity and feelings of satisfaction are rare.

The relativity is such that this biodiversity could also be experienced and perceived as negative. We should not allow the current interest in biodiversity to let us forget the battles waged by societies for centuries against certain elements of biodiversity which were dangerous for man, domestic animals or plants. Based on the debates and discussions that they generated, the very notions of "harmful species" and "invasive species" bear out the relativity of biodiversity perceptions. This relativity does not arise merely with regard to the past.

So much relativity cannot be used to refute all willingness to preserve this biodiversity on the grounds that it would be impossible to value it accurately. The issue really boils down to analysing the resources and means for 
a renewed care-based approach. Such an approach would lead to a rethink of biodiversity spaces and territories. First spaces because, as we have already pointed out, ordinary biodiversity eludes traditional bases for zoning and categorisation. These reflections could be applied to rural spaces and woodland. Research carried out in the forests of Gâtinais south of Paris (Linglart \& Blandin, 2006; Linglart, 2000) has pointed up the complexity of these woodland structures both from an ecological standpoint and from the perspective of the stakeholders who own and use them. Situated between two vast certified forests with high ecological value, the wooded islands of Gâtinais studied by Linglart and Blandin (2006), a priori without interest, are in fact places of real diversity resulting from multiple practices and inheritances produced by numerous small owners. Ordinary biodiversity is fabric, interstice and mosaic all at once and largely eludes any predefined spatial categorisation be it ecological or territorial.

This freeing up of space leads on to an analysis of the multiplicity of the stakeholders involved. The protectionist approach favouring defensive measures or orders from the top (coming from international or national bodies) no longer works. We need to focus more on stakeholder motivation and the network of relationships (or potential relationships) that they forge around biodiversity and ultimately on the approaches that make sense in a given territory. Although biodiversity remains a hard-to-define unfamiliar notion for citizens, it is nevertheless perceived as important. Research carried out as part of the previous programme (Brédif et al., 2010) also highlighted the sensitivity of forestry stakeholders in the Morvan and Médoc regions to biodiversity compartments. All of this research confirms individuals' attachment to and affinity (Lawrence, 2006; Londeau \& Straka, 2013) with living matter, what E. Wilson terms biophilia (Wilson, 1984). A shared approach to ordinary biodiversity partially eludes largely constraining approaches and focuses on the applications designed around sharing responsibility for this living fabric. Contrary to the findings of Hardin (1968) in the Tragedy of the Commons, we really need to move towards a strengthening of social capital as suggested by Ostrom (2000). Reconciliation-a theme much in vogue at present-is not merely a reconciliation with some forgotten nature (Fleury \& PrévostJulliard, 2012), but more of a reconciliation between stakeholders as part of an approach that goes beyond the asymmetry of knowledge and power that all too often prevails in pro-biodiversity policies.

\section{Favouring a Care-Based Approach to Biodiversity: Initial Lessons from the Plateau de Millevaches}

We tackled this topic of ordinary biodiversity and its management during our OPTIQ-Biodiversité (tools and processes for integrated territorialisation of biodiversity) research-action project, funded by the French Ecology Ministry as part of its Biodiversity and Forestry Management programme (Biodiversité et Gestion forestière).

This cross-disciplinary project brings together teams from Institut Technologique FCBA, the LADYSS research unit and École Normale Supérieure de Lyon and is being deployed in the Limousin region on the Plateau de Millevaches which forms the north-western limit of the Massif Central mountain range. The Plateau's landscape has been totally transformed (Périgord, 1993) over the past 100 years and is very sparsely populated today (18 inhabitants $/ \mathrm{km}^{2}$ ). Livestock grazing and sheep farming used to predominate but there has been a massive exodus since the end of the nineteenth century through the first-half of the twentieth century. Wasteland has been replanted with coniferous trees on a huge scale and over two-thirds of the Plateau is now covered with forests. For the past few decades, the Douglas fir (Pseudotsuga menziesii) has become increasingly dominant in higher up areas. A series of legislation has sought to structure the protection of natural species deemed to be remarkable and a national park was created in 2004 covering 113 communes, 38,000 inhabitants and 300,000 hectares. More specifically, the research project focused on a specific area, the Plateau de Gentioux (282 km², 2220 inhabitants) on the north of the Plateau de Millevaches.

\subsection{How to Assess Ordinary Biodiversity in Concrete Terms}

Anyone seeking to tackle diversity from the perspective of stakeholder commitment is in for a big surprise: while it is difficult to confer ordinary biodiversity - whether monetised or not—with an "objective" scientifically-grounded value, it is just as tricky to trust in the subjectivity of stakeholders. First question, first challenge: what exactly are we talking about? Should we trust science to devise a benchmark for the ordinary biodiversity of a territory before submitting it to the relevant stakeholders for qualification and evaluation? And this while secretly hoping to come up with a hierarchical ranking of multiple species, habitats, ecosystems and other landscapes as a means of defining or forcing "objective agreement" on what needs to be looked for and what needs 
to be done? Or should we move forward without any preconceived benchmark, pre-defined classification or inventory, based primarily on the spontaneous declarations of stakeholders?

This initial dilemma quickly came to the fore following interviews conducted with naturalists and recognised specialists in Limousin. While it was hoped that these interviews would help in drawing up a list of relevant inputs to be used in assessing ordinary biodiversity, what they actually highlighted was the difficulty and downright impossibility of such an approach. For these different experts, any biodiversity worthy of interest resided in the last surviving remarkable habitats on the Plateau—bogs, wetlands, rocky places of refuge for bats, copses of hardwood trees, etc. Otherwise, they highlighted the mediocrity of the biodiversity present which they assessed in terms of the variety and rarity of the species or habitat. Moreover, plantations of Douglas fir are considered a quasi-desert of biodiversity. Hardwood forests are viewed more favourably even though, with the exception of the boreal owl, the species residing there may be found just about anywhere. As regards moorland, "specific biodiversity is relatively meagre even though it does contribute to biological diversity on a regional level”. Apart from these few remarkable aspects, specialists focus primarily on the considerable upheaval that has taken place on the Plateau de Millevaches over the past few decades and the fact that the "closure" of these habitats has run down the overall level of biodiversity (linked in large part to open habitats). Otherwise, they deem the ordinary biodiversity of the Plateau de Millevaches to be relatively banal and of little interest. As such, it is hard to construct any "objective" benchmark of ordinary biodiversity that could subsequently be submitted to local stakeholders for assessment.

However, the other approach soon turned out to be tricky as well albeit for other reasons. A series of one-onone interviews conducted with different local stakeholders demonstrated that biodiversity aspects of interest vary greatly from one person to another. Whereas certain forest owners or stakeholders are hung up on various species of trees, inhabitants, environmental defence associations or elected representatives pay more attention to landscape-related aspects, colours and fragrances, the presence of birds of prey, trout or pearl mussels in the rivers, soil fertility, etc. One positive point that emerges from the various interviews is that biodiversity is indeed of great importance to those surveyed although they often latch on to quite specific aspects that are closely related to their preoccupations or practices. Furthermore, such biodiversity elective affinities largely emanate from personal relationships/experiences and those contacted confirmed that they have rarely had the possibility of framing these or discussing them in other terms. Conversely, drawing upon such varied and even elusive bases, how is it possible to find one's way around this question of ordinary biodiversity? Are we inexorably restricted to the most extreme relativism where each stakeholder sees things from their own narrow perspective?

A few months later a working group was set up with the support of local representatives in which 17 stakeholders participated. Each of the participants was invited to come up with two key words characterising biodiversity on the Plateau along with an explanation of their choice, what these words mean to them and in what way they consider these aspects of biodiversity to be important for the territory. At a first glance, the sheer plurality of inputs is dizzying (Figure 1). How can we make sense of such plurality?

Starting with the expressions formulated in groups by the different stakeholders and the data gathered in the one-on-one interviews, the research team sought to identify the main reasons given-disregarding differences in individual expressions - for stating how the various different aspects of biodiversity mentioned are actually important for the Plateau de Gentioux. We have referred to these as the key motivating factors in the rest of this article. Once this analysis was complete, five key motivating factors emerged (Figure 2):

1) Responsibility. "We have to deal with it because we are responsible" is a concept that crops up very frequently, particularly for aspects related to water and water quality as well as for certain endemic species.

2) Biodiversity as a sign of the quality of a territory that currently has no future was a motivating factor in itself for a number of people: "a wealth of biodiversity is the sign of a quality territory with sound and healthy practices"; "it is a source of pride in how living matter is handled both now and in the future".

3) It is a key component in quality of life and well-being. Landscape and the balance and diversity of land-use together with long-term population management underpin this component. This dimension appears all the more important as a lot of people have elected to live on the Plateau precisely for the quality of life on offer there.

4) Biodiversity may also provide resources in the form of products (wood for heating and carpentry, mushrooms, honey, etc.) and services (air quality, attractiveness for tourism, population resilience). Surprisingly, these aspects were barely dealt with during the first group meeting.

5) Biodiversity also contributes to territorial strategy and identity. It boosts willingness and a project based around autonomy for people who have chosen to live there (energy autonomy, a less consumerist and heterony- 


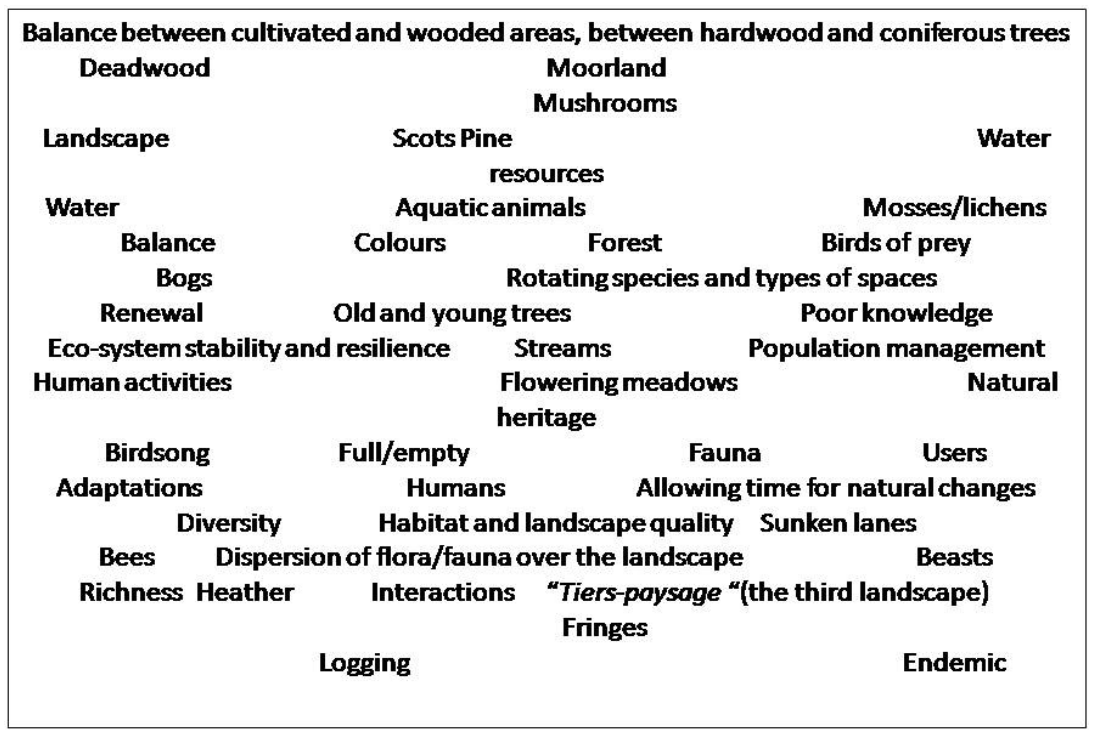

Figure 1. Biodiversity in the stakeholders' own words. The words are indicated at random as expressed by the stakeholders.

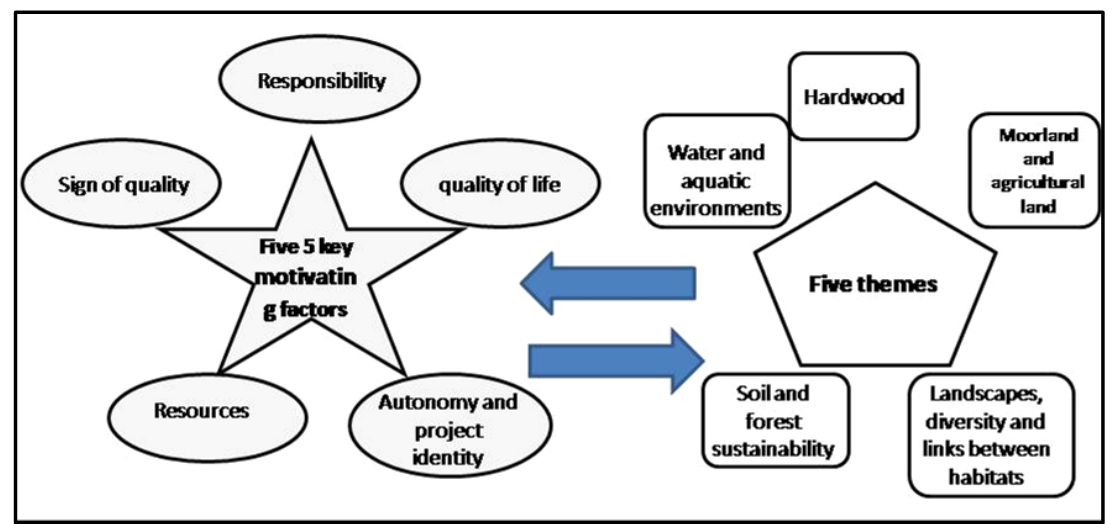

Figure 2. The stakeholders agree on 5 key motivating factors that have got them involved in biodiversity on the Plateau de Gentioux. By referring to these substantive grounds, they come up with five themes that are of particular strategic or critical importance for the territory.

mous way of life based on greater solidarity).

These key motivating factors, initially expressed by different stakeholders based on singular aspects or illustrations, were subsequently presented to all stakeholders involved in the research programme. They agreed upon the joint importance of these five motivating factors, refusing to rank them because they considered that they should be treated from an overall perspective. They ultimately correspond to the substantive grounds on which local stakeholders consider that biodiversity is genuinely important. They had never before had an opportunity to express these reasons in public and they derive their full meaning from the fact that the stakeholders agree among themselves that they are actually significant for the territories they concern. By recognising them together, they were ultimately affirming or reaffirming the project that binds them together and reinforcing its shared character. Moreover, we should stress that it was by asking the different stakeholders which aspects of biodiversity were most important or posed most problems with regard to these five motivating factors, that they were gradually able to elucidate these five broad themes specific to the Plateau's characteristics. Just as the benchmark for ordinary biodiversity which appeared so difficult to obtain at the beginning of the process could ultimately be developed and needs to be considered within a logic spanning fundamental biodiversity factors on the one hand, and the broad themes of biodiversity on the other, so in the case in point, these cannot be reduced 
merely to a given set of species or habitats.

\subsection{From the Risk of Absolute Relativism to a Form of Complexity That Is Both Organised and Circumscribed}

In a nutshell, the risk of ending up with some form of unlimited relativism where everyone defends their own specific viewpoints and biodiversity aspects was ultimately avoided. After a few meetings, a form of decanting took place that helped to contain the multiple aspects and initial complexity of the topic. It became possible to get beyond stakeholders' initial fragmented vision to obtain grouped and enriched opinions and comments from one and all. The risk of absolute relativism gave way to a form of restricted relativism because it was contained within reasonable proportions: obviously, the stakeholders focused primarily on certain aspects of biodiversity, however, these elective affinities may be related back to the most basic, cross-disciplinary motivating factors that the stakeholders have in common, aside from initial differences in expressions of biodiversity and its related aspects. Incidentally, these various aspects were actually quite limited in number and may be grouped into broad categories or themes deemed to be decisive for the territory as a whole by the bulk of the stakeholders. The initial question, "What do we mean by ordinary biodiversity?" ultimately became "What does biodiversity mean for you?" And the response assumes a joint reflexion upon the key cross-disciplinary motivating factors and themes corresponding to compartments of biodiversity whose relevance is recognised by the stakeholders themselves.

Finally, it would appear that this question of motivating factors as understood here constitutes another way of dealing with the value of biodiversity: not any sort of absolute or universal value but a value that makes complete sense for local stakeholders and the project to which they subscribe. Better still, it fleshes out the project insofar as the stakeholders have an opportunity - to pool experiences and motivating factors and to negotiate among themselves—-that they would not normally have had (Beierle, 2002; Turnhout et al., 2010).

\subsection{Stakeholders Endowed with Expertise: How to Take the Future of a Territory Back in Hand in Order to Manage Biodiversity More Effectively?}

The approach in the subsequent meetings was to ask participants to collectively come up with a strategic diagnostic review of the situation with regard to the five themes selected for qualifying biodiversity. For each theme, the idea was to characterise the situation observed, highlight any problems or dissatisfaction and try to assess these by evaluating the system for action in terms of its capacity to correct any problems identified. By crossreferencing the different thematic diagnoses, we came up with a more general diagnostic review. It is not possible to describe this phase in the requisite detail using the format employed here but the major findings are as follows:

First, the actors felt that virtually all of the key qualities linked to living matter that are important to them are not under any control whatsoever. They blame a number of societal and economic developments together with changes in government, regional and local policies that have increased pressure on the Plateau's forests-especially hardwood trees, but coniferous trees as well. The general approach to forest management is characterised by its non-sustainability from 1) an ecological perspective (deterioration in soil fertility; copses of hardwood systematically harvested and the land replanted with coniferous trees; the Douglas fir monoculture fails to take any account of health risks or climate change) 2) an economic perspective (trees being harvested at an increasingly young age without any real effort to replenish forestry resources; absence of any financial return for the territory) or 3) a social perspective (initiatives from sector stakeholders or public institutions that support the sector itself without taking any real account of local inhabitants' wishes). These different impacts have combined to gradually widen the gap between the expectations of local inhabitants and actual practices in the forestry-timber-paper sector, culminating in increased local dissatisfaction.

A number of owners present at the meetings showed how this problem of the relationship between sector and territory is compounded by another problem: a lot of forest owners today are "dormant" owners and no longer play any active role. This is because they are no longer interested or because they cannot eke out a role based on the operating arrangements currently proposed by the major forestry operators or because they are completely at a loss as to how to manage their forests in a satisfactory manner. No sufficiently well structured offering currently exists that would allow these landowners to make an active contribution to the quality of the territory or the competitiveness of the sector. 
By combining these two thematic diagnoses, the inhabitants of Plateau de Gentioux would appear to be confronted with the following problem: a sparsely populated upland area where the inhabitants are currently being squeezed by an unsustainable - or barely sustainable - approach to forestry production on the one hand, and by a nebulous/dormant group of landowners that make no contribution to the development of the Plateau on the other. In other words, both the local inhabitants and those in charge of the Plateau feel that the future of the territory-particularly its biodiversity-related aspects—is largely beyond their control.

Based on these considerations, we can highlight three factors. First, we should stress that it would be inaccurate to reduce local stakeholder biodiversity-related competencies merely to local knowledge or to see them at best as adhering to "subjective" representations of the diversity of living matter. Not only were the stakeholders with whom we worked highly focused on biodiversity, they also possess genuine expertise in understanding the current state of this biodiversity and conducting a refined analysis of the arrangements that have produced the current system as well as in how to move things forward (Miller \& Hobbs, 2002; Turnhout et al., 2010). And while such expertise is not exhaustive, it stresses the key economic, organisational and socio-political determinants that will condition the biodiversity of tomorrow at least as much as its physical and ecological determinants. Second, for those who know how to identify and combine expertise among a range of different local stakeholders within a suitably adapted approach, it becomes possible to produce an enhanced and contextualised strategic diagnostic review of the biodiversity situation and potential. This diagnostic review may be used to highlight the major problem with which a territory is confronted. In the case in point, the problem stems from the fact that the territory is subject to external pressure on these forests without local stakeholders being able to take matters in hand. Simply helping a fraction of local stakeholders to come to this joint realization and analyzing why biodiversity is important for the territory allowed the latter to sketch out a shared project, whereas up to then they had merely been putting up with things while experiencing a sense of powerlessness. They will now be able to move on to the next stage which consists in presenting this project to actors within the forestry sector and public institutions to reflect upon the means required to obtain a better fit between sector-based approaches and local mindsets within a negotiated contract, and to reflect upon the conditions and means that would make it possible to organise a forestry management offering likely to involve a certain number of currently inactive landowners. This perspective is likely to be of interest to stakeholders in the forestry sector confronted with a problem of disinvestment that they do not know how to deal with.

\section{Conclusion}

The research being conducted on the Plateau de Gentioux is not complete. We still have to establish to what extent a project devised by a small group of local stakeholders which could actually serve as a think-tank and forum for exchangeing with stakeholders and institutions operating at a higher level on the Plateau de Millevaches and in Limousin. This approach has already demonstrated that-contrary to what we often hear in relation to biodiversity - the problem cannot be reduced simply to a question of awareness and a change in mindsets; with the corollary that the issue ultimately revolves around shrewd use of the carrot and stick to move behaviour and practices in the direction intended. In this case, a significant portion of local stakeholders are very much concerned by the components and key aspects of the ordinary biodiversity existing in and around their forests (Fischer \& Young, 2007). But conditions are not ripe for transforming these concerns and representations into active, dynamic management of the diversity of living matter. Faced with the plethora of operators conditioning the future of forests and the indeterminate nature of some of them, local stakeholders are being subjected to changes and transformations in their territory (Miller et al., 2007). And it is more difficult to talk about these issues together and to try to get a grip on matters insofar as each stakeholder has their own specific relationship with this diversity of living matter. So each stakeholder is faced with their own sensitivities and the absence of any clear signs of a broader mobilisation in favour of the living environment, thus accentuating a feeling of powerlessness to act. This also shows how the work of strategic facilitation that underpins this research-action project can have a determining influence on how the whole question of management and protection of ordinary biodiversity in forest is tackled.

\section{Main Results}

- Considering ordinary biodiversity as a key point for forest managment which involves a radical rethink of long-dominant conservation and/or land banking policies. 
- Considering local stakeholders as expert of this ordinary forest biodiversity and more widely of the regional context.

- Considering new tools to be deployed in conjunction with regional and local stakeholders that will provide long-term sustainable solutions for biodiversity and for local and regional development more generally.

- Highlighting the possibilities for a shared caring for this forest biodiversity.

\section{References}

Arnstein, S. (1969). A Ladder of Citizen Participation. Journal of the American Institute of Planners, 35, $216-224$. http://dx.doi.org/10.1080/01944366908977225

Barbault, R. (2006). Un éléphant dans un jeu de quilles. L’homme dans la biodiversité. Paris: Seuil.

Bastolla, U., Fortuna, M. A., Pascual-García, A., Ferrera, A., Luque, B., \& Bascompte, J. (2009). The Architecture of Mutualistic Networks Minimizes Competition and Increases Biodiversity. Nature, 458, 1018-1020. http://dx.doi.org/10.1038/nature07950

Beierle, T. C. (2002). The Quality of Stakeholder-Based Decisions. Risk Analysis, 22, 739-749. http://dx.doi.org/10.1111/0272-4332.00065

Blandin, P. (1992). De l'écosystème à l'écocomplexe. In M. Jollivet (Ed.), Entre Nature et Société, les passeurs de frontière (pp. 267-279). Paris: Editions du CNRS.

Brédif, H., Arnould, P., \& Bailly, A. (2010). Recherche des voies, conditions et moyens d’une prise en charge renforcée des enjeux de la biodiversité par les propriétaires et les gestionnaires forestiers. In I. Bonhême, \& C. Millier (Eds.), Programme "Biodiversité et Gestion Forestière", résultats scientifiques et acquis pour les gestionnaires et décideurs, projets 2005-2009 (pp. 29-43). Paris: GIP Ecofor-MEEDDM.

Chevassus-au-Louis, B. (2012). Les services écologiques des forêts : définition des concepts, origine et typologies. Revue Forestière Française, LXIV, 3, 213-223.

Fahrig, L., Baudry, J., Brotons, L., Burel, F. G., Crist, T. O., Fuller, R. J., Sirami, C., Siriwardena, G. M., \& Martin, J.-L. (2010). Functional Landscape Heterogeneity and Animal Biodiversity in Agricultural Landscapes. Ecology Letters, 14, 101-112. http://dx.doi.org/10.1111/j.1461-0248.2010.01559.x

Fischer, A., \& Young, J. C., (2007). Understanding Mental Constructs of Biodiversity: Implications for Biodiversity Management and Conservation. Biological Conservation, 136, 271-282. http://dx.doi.org/10.1016/j.biocon.2006.11.024

Fleury, C., \& Prévost-Julliard, A. C. (2012). L’exigence de la réconciliation. Biodiversité et société. Paris: Editions Fayard.

Foltête, J.-C., Clauzel, C., Vuidel, G., \& Tournant, P. (2012). Integrating Graph-Based Connectivity Metrics into Species Distribution Models. Landscape Ecology, 27, 557-569. http://dx.doi.org/10.1007/s10980-012-9709-4

Gaston, K. J., \& Fuller, R. A. (2008). Commonness, Population Depletion and Conservation Biology, Trends in Ecology \& Evolution, 23, 1419-1426. http://dx.doi.org/10.1016/j.tree.2007.11.001

Godet, L. (2010). La “nature ordinaire dans” le monde occidental. L’Espace Géographique, 4/10, 295-308.

Hardin, G. (1968). The Tragedy of the Commons. Science, 162, 1243-1248. http://dx.doi.org/10.1126/science.162.3859.1243

Julliard, R., Clavel, J., Devictor, V., Jiguet, F., \& Couvet, D. (2006). Spatial Segregation of Specialists And Generalists in Bird Communities. Ecology Letters, 9, 1237-1244. http://dx.doi.org/10.1111/j.1461-0248.2006.00977.x

Lawrence, A. (2006). No Personal Motive? Volunteers, Biodiversity, and the False Dichotomies of Participation. Ethics, Place and Environment, 9, 279-298. http://dx.doi.org/10.1080/13668790600893319

Lennon, J. J., Beale, C. M., Reid, C., Kent, M., \& Pakeman, R. (2011). Are Richness Patterns of Common and Rare Species Equally Well Explained by Environmental Variables? Ecography, 34, 529-539.

http://dx.doi.org/10.1111/j.1600-0587.2010.06669.x

Linglart, M. (2000). La biodiversité végétale des îlots boisés en terre de grande culture. Approche ethnoécologique, exemple du Gâtinais occidental. Thèse de doctorat en ethnoécologie, Muséum National d’Histoire Naturelle.

Linglart, M., \& Blandin P. (2006). La biodiversité des petits bois, “anthroposystèmes insulaires” dans les plaines de grande cultures: L’exemple du Gâtinais occidental. Annales de Géographie, 651, 569-596. http://dx.doi.org/10.3917/ag.651.0569

Londeau, A. C., \& Straka, T. J. (2013). Family Forest Owners’ Motivation to Control Understory Vegetation: Implications for Consulting Forestry. Open Journal of Forestry, 3, 99-103. http://dx.doi.org/10.4236/ojf.2013.34016

Lynam, T., de Jong, W., Sheil, D., Kusumanto, T., \& Evans, K., (2007) A Review of Tools for Incorporating Community Knowledge, Preferences, and Values into Decision Making in Natural Resources Management. Ecology and Society, 12, 5.

MacArthur, R. H., \& Wilson, E. O. (1967). The Theory of Island Biogeography. Princeton, N.J.: Princeton University Press, 
203 p.

Mimet, A., Houet, T., Julliard, R., \& Simon, L. (2013). Assessing Functional Connectivity: A Landscape Approach for Handling Multiple Ecological Requirements. Methods in Ecology and Evolution, 4, 453-463. http://dx.doi.org/10.1111/2041-210x.12024

Miller, J. R., \& Hobbs, R. J. (2002). Conservation Where People Live and Work. Conservation Biology, 16, 330-337. http://dx.doi.org/10.1046/j.1523-1739.2002.00420.x

Ostrom, E. (2000). Reformulating the Commons. Swiss Political Science Review, 6, 29-52. http://dx.doi.org/10.1002/j.1662-6370.2000.tb00285.x

Périgord, M. (1993). La notion de paysage de montagne en Limousin. Norois, 159, 481-496. http://dx.doi.org/10.3406/noroi.1993.6503

Stringer, L. C., Prell, C., Reed, M. S., Hubacek, K., Fraser, E. D. G., \& Dougill, A. J. (2006). Unpacking “Participation” in the Adaptive Management of Socio-Ecological Systems: A Critical Review. Ecology and Society, 11, 39.

Reed, M. S. (2008). Stakeholder Participation for Environmental Management: A Literature Review. Biological Conservation, 141, 2417-2431. http://dx.doi.org/10.1016/j.biocon.2008.07.014

Rowe, G., \& Frewer, L. (2000). Public Participation Methods: A Framework for Evaluation. Science Technology and Human Values, 25, 3-29. http://dx.doi.org/10.1177/016224390002500101

Thompson, R., \& Starzomski, B. M. (2006). What Does Biodiversity Actually Do? A Review for Managers and Policy Makers. Biodiversity and Conservation, 16, 1359-1378. http://dx.doi.org/10.1007/s10531-005-6232-9

Turnhout, E., Van Bommel, S., \& Aarts, N. (2010). How Participation Creates Citizens: Participatory Governance as Performative Practice. Ecology and Society, 15, 26-35.

Wilson, E. O. (1984). Biophilia. Cambridge: Harvard University Press. 